\title{
Cytokine-induced changes in the gene expression profile of a human cerebral microvascular endothelial cell-line, hCMEC/D3
}

Miguel Alejandro Lopez-Ramirez ${ }^{1,3}$, David Kingsley Male ${ }^{1}$, Chunfang Wang ${ }^{1}$, Basil Sharrack², Dongsheng Wu and Ignacio Andres Romero ${ }^{1 *}$

\begin{abstract}
Background: The human cerebral microvascular endothelial cell line, hCMEC/D3, has been used extensively to model the blood-brain barrier (BBB) in vitro. Recently, we reported that cytokine-treatment induced loss of brain endothelial barrier properties. In this study, we further determined the gene expression pattern of hCMEC/D3 cells in response to activation with TNFa and IFNY.

Findings: Using a microarray approach, we observed that expression of genes involved in the control of barrier permeability, including inter-brain endothelial junctions (e.g. claudin-5, MARVELD-2), integrin-focal adhesions complexes (e.g. integrin $\beta 1$, ELMO-1) and transporter systems (e.g. ABCB1, SLC2A1), are altered by pro-inflammatory cytokines.

Conclusions: Our study shows that previously-described cytokine-induced changes in the pattern of gene expression of endothelium are reproduced in hCMEC/D3 cells, suggesting that this model is suitable to study inflammation at the BBB, while at the same time it has provided insights into novel key molecular processes that are altered in brain endothelium during neuroinflammation, such as modulation of cell-to-matrix contacts.
\end{abstract}

Keywords: Blood-brain barrier, Transcriptome, Cytokines, Transporter systems, Inter-brain endothelial junctions, Integrin-focal adhesions

\section{Findings}

\section{Introduction}

Cerebral endothelial cells (CEC) constitute the major element of the highly specialized vasculature of the central nervous system (CNS) that contributes to the blood-brain barrier (BBB). In vitro models have complemented animal and human studies in our current understanding of $\mathrm{BBB}$ function. To date, the best characterized in vitro human BBB model is based on the human cerebral microvascular endothelial cell line, hCMEC/D3. Indeed, recent studies on hCMEC/D3 cells have elucidated bacterial and viral CNS invasion mechanisms [1,2], leukocyte trafficking [3], regulation of transporters $[4,5]$ and signalling pathways controlling CEC paracellular permeability [6-9]. Here, we

\footnotetext{
* Correspondence: i.romero@open.ac.uk

${ }^{1}$ Department of Life, Health \& Chemical Sciences, The Open University, Milton Keynes MK7 6AA, UK

Full list of author information is available at the end of the article
}

provide further insights into the molecular mechanisms associated with barrier dysfunction by analyzing the gene expression pattern in cytokine-activated hCMEC/D3 cells using mRNA microarray analysis.

\section{Materials and methods \\ Culture conditions}

hCMEC/D3 cells were cultured in EGM-2 MV medium (Lonza, Slough Wokingham, UK) and supplemented with the following components obtained from the manufacturer: $0.025 \%(\mathrm{v} / \mathrm{v})$ rhEGF, $0.025 \%(\mathrm{v} / \mathrm{v})$ VEGF, $0.025 \%(\mathrm{v} / \mathrm{v})$ IGF, $0.1 \%(\mathrm{v} / \mathrm{v})$ rhFGF, $0.1 \%(\mathrm{v} / \mathrm{v})$ gentamycin, $0.1 \%(\mathrm{v} / \mathrm{v})$ ascorbic acid, $0.04 \%(\mathrm{v} / \mathrm{v})$ hydrocortisone and $2.5 \%(\mathrm{v} / \mathrm{v})$ foetal bovine serum (FBS). Cells were seeded onto flasks supplied by Greiner Bio-one (Gloucestershire, UK), previously coated with collagen, and maintained at $37^{\circ} \mathrm{C}$ in $95 \%$ air and 5\% $\mathrm{CO} 2$ until confluence. 


\section{RNA extraction and mRNA microarray analysis}

hCMEC/D3 cells were grown on collagen-coated six-well plates and treated with $10 \mathrm{ng} / \mathrm{ml}$ of TNF $\alpha$ and IFN $\gamma(\mathrm{R} \& \mathrm{D}$ systems, Abingdon, Oxon, UK) for $24 \mathrm{~h}$, while control cells received the vehicle solution. Cells were washed once with pre-warmed Hank's balanced salts solution. Total RNA from three biological replicates was isolated using miRNeasy mini kit (Qiagen, Crawley, West Sussex, UK) according to the manufacturer's protocols. The RNA was re-suspended using RNase-free water. The quantity (NanoDrop 1000 spectrophotometer) and the quality (2100 Bioanalyzer, RNA 6000 Pico LabChip; Agilent, Palo Alto, CA, USA) were assessed for each RNA sample. For each biological sample $100 \mathrm{ng}$ of total RNA was used, obtained from approximately $1.5 \times 10^{6}$ cells. For mRNA profiling, Ambion ${ }^{\star}$ TotalPrep 96 RNA Amplification kit and Illumina hybridisation protocols were carried out by Cambridge Genomic Services (Cambridge, UK). The analysis was run using LUMI and LIMMA packages ( $\mathrm{R}$ Bioconductor). A quantile normalization was performed and a number of quality plots were generated to assess the quality of the data. Differences between control and treated cells were estimated when a gene signal in two or more replicates is at the background level. Instead of using numerical values, we indicated these genes as upregulated (+) or downregulated (-) in cytokine-treated cells. Detailed procedures and complete data are available at the Gene Expression Omnibus (www. ncbi.nlm.nih.gov/geo) under accession number GSE45880.

\section{Quantitative RT-PCR}

Complementary DNA was obtained using reverse transcriptase (Promega, Madison, WI) with random primers according to the manufacturer's protocol. SYBR Green real-time PCR (Qiagen, Manchester, UK) was used to determine the relative levels of the genes analyzed (Table 1). The reaction was then placed in a thermal cycler (DNA engine Opticon 2; Bio-Rad, Hercules, CA, USA) using an initial step at $95^{\circ} \mathrm{C}$ for $15 \mathrm{~min}$, followed by 40 cycles $(15 \mathrm{~s}$ at $94^{\circ} \mathrm{C}, 30 \mathrm{~s}$ at $55^{\circ} \mathrm{C}$, and $30 \mathrm{~s}$ at $\left.72^{\circ} \mathrm{C}\right)$. The $2^{-\Delta \Delta C \mathrm{~T}}$ method was used for analysis of the data.

Table 1 Primers used for quantitative RT-PCR on hCMEC/D3 cells

\begin{tabular}{|c|c|c|c|c|c|}
\hline Category & Gene & Forward and reverse primers & Gene entrez & Start & Stop \\
\hline \multirow[t]{6}{*}{ Cell-cell contact } & $\mathrm{CDH} 5$ & F: 5'CAGATCTCCGCAATAGACAAGG3' & NM_001795.2 & 1563 & 1585 \\
\hline & & R: 5'CGTGATTATCCGTGAGGGTAAAG3' & & 1637 & 1660 \\
\hline & MARVELD2 & F: 5'GTACTCGTGGTTGCTGGATTAG3' & NM_001038603.2 & 840 & 862 \\
\hline & & $\mathbf{R}: 5^{\prime} G C C A C C A A T T A G A G T C C A G A A G 3 '$ & & 921 & 943 \\
\hline & ANXA2 & F: 5'GAAACAGCCATCAAGACCAAAG3' & NM_001002858.2 & 254 & 276 \\
\hline & & R: 5'TGGTAGGCGAAGGCAATATC3' & & 335 & 355 \\
\hline \multirow[t]{6}{*}{ Cell-to-matrix adhesion } & ITGB1 & F: 5'CATGTTGTGGAGAATCCAGAGT3' & NM_002211.3 & 2367 & 2389 \\
\hline & & R: 5'GCAGTAATGCAAGGCCAATAAG3' & & 2445 & 2467 \\
\hline & ELMO1 & F: 5'GACCTGGGTTGAGATGATATGG3' & NM_014800.10 & 4407 & 4429 \\
\hline & & R: 5'GAGTGCTCTGATGGGAAGAAG3' & & 4483 & 4504 \\
\hline & $\mathrm{FHL} 2$ & F: 5'CAGAAACTCACTGGTGGACAA3' & NM_201555.1 & 792 & 813 \\
\hline & & R: 5'ATTCCTGGCACTTGGATGAG3' & & 870 & 890 \\
\hline \multirow[t]{6}{*}{ Chemokines/cell adhesion molecules } & $\mathrm{CCL} 2$ & F: 5'GGCTGAGACTAACCCAGAAAC3' & NM_002982.3 & 13 & 34 \\
\hline & & R: 5'GAATGAAGGTGGCTGCTATGA3' & & 108 & 129 \\
\hline & VCAM-1 & F: 5'CATTTGACAGGCTGGAGATAGA3' & M73255.1 & 1217 & 1239 \\
\hline & & R: 5'CTCTTGGTITCCAGGGACTT3' & & 1297 & 1317 \\
\hline & CEACAM1 & F: 5'CTACCTGTAGGATCAGGGTCTAA3' & NM_001712.4 & 1991 & 2014 \\
\hline & & R: 5'CTAGTTGCTTCTAGTGGGTTCTC3' & & 2069 & 2092 \\
\hline \multirow[t]{6}{*}{ Transporters } & $\mathrm{ABCB} 1$ & F: 5'TGCAGGTACCATACAGAAACTC3' & NM_000927.4 & 3264 & 3286 \\
\hline & & R: 5'ACCGGAAACATCCAGCATAG3' & & 3349 & 3369 \\
\hline & $\mathrm{SLC} 2 \mathrm{~A} 1$ & F: 5'GGACAGGCTCAAAGAGGTTATG3' & NM_006516.2 & 3217 & 3239 \\
\hline & & R: 5'AGGAGGTGGGTGGAGTTAAT 3' & & 3309 & 3329 \\
\hline & $\mathrm{SLC} 2 \mathrm{~A} 3$ & F: 5'CTTAGTTCTCACTGTTCCСTCTG3' & NM_006931.2 & 3397 & 3420 \\
\hline & & R: 5'TCCCAAAGTGCTGGGATTAC3' & & 3480 & 3500 \\
\hline \multirow[t]{2}{*}{ Internal standard } & ACTB & F: 5'GGACCTGACTGACTACCTCAT 3' & NM_001101.3 & 633 & 654 \\
\hline & & R: 5'CGTAGCACAGCTTCTCCTTAAT 3' & & 718 & 740 \\
\hline
\end{tabular}




\section{Bioinformatic analysis}

DAVID bioinformatics [10] tool was used to create the functional annotation clustering from microarray analysis by using KEGG pathways. Transcripts with more than one probe represented in the mRNA microarray that showed contradictory results in the direction of changes in expression levels between control cells and cells treated with TNF $\alpha$ and IFN $\gamma$, were considered as not showing any changes.

\section{Statistical analysis}

The statistical analysis for the mRNA microarray was performed using pairwise comparisons and false discovery rate. The data set was filtered before normalisation, removing any probes that were not successfully detected (detection $P$ was less than 0.01 ) in at least one sample. Statistical significance was considered if $P$ was less than 0.01 for KEGG analysis or 0.05 for barrier-related gene analysis determined by LIMMA software. For quantitative RT-PCR, statistical significance was considered if $P$ was less than 0.05 as determined by paired, one-tailed Student's $t$ test.

\section{Results}

Pro-inflammatory cytokine modulation of gene expression profile of cultured human brain endothelium In order to identify the major molecular processes involved in cytokine-induced altered CEC phenotype, we analyzed the changes in gene expression in hCMEC/D3 cells after stimulation with TNF $\alpha$ and IFN $\gamma$ for $24 \mathrm{~h}$ using mRNA array. By considering the transcripts that were positively regulated with at least a two-fold change over unstimulated cells (404 genes, $P<0.01$ ) we identified three statistically significant biological process associated with antigen presentation (human leukocyte antigen, HLA)/cellular adhesion (cell adhesion molecules, CAM) (20 genes), cytokine/chemokine activity (28 genes) and cytokineinduced signalling pathways (16 genes) (Additional file 1: Table S1 TNF $\alpha$ and IFN $\gamma$-induced modulation of gene expression profile of cultured human brain endothelium). Other minor functional categories identified were associated with apoptosis [11] and complement/coagulation cascades [12] (Additional file 1: Table S1). In addition, Additional file 1: Table S1, shows cytokine-induced increase of 24 mRNA transcripts associated with interleukin and decrease of 7 genes in hCMEC/D3 cells. We validated cytokine-induced changes in the levels of 3 mRNAs in hCMEC/D3 cells including CCL2, VCAM-1 and CEACAM-1 (Figure 1A). Overall, these results indicate that proinflammatory cytokines trigger changes in the gene expression pattern of hCMEC/D3 cells with roles in facilitating leukocyte adhesion and transmigration across the brain endothelium.

\section{Pro-inflammatory cytokine modulation of transcripts related to BBB permeability}

Recently, we reported that TNF $\alpha$ alone or in combination with IFN $\gamma$ trigger signalling pathways that result in loss of barrier properties by negative modulation of cell-cell contacts [8]. Hence, we investigated genes involved in the control of the paracellular pathway of brain endothelium. Additional file 2: Table S2 (TNF $\alpha$ and IFN $\gamma$-induced modulation of transcripts related to BBB permeability) shows cytokine-induced decrease of 27 mRNA transcripts associated with the junctional complex molecules (JCM), and an increase of 14 genes in hCMEC/ D3 cells. Furthermore, brain endothelial barrier properties may be determined by cellular attachment to the extracellular matrix [13]. We observed that stimulation with TNF $\alpha$ and IFN $\gamma$ induced changes in the expression pattern of focal adhesion (FA) genes in hCMEC/D3 cells. Cytokines reduced the expression of 45 transcripts and increased of 43 transcripts out of the 126 FA genes identified in hCMEC/D3 cells (Additional file 2: Table S2). In addition, 10 integrin genes out of the 18 integrin transcripts identified in hCMEC/D3 cells were downregulated by cytokines, whereas only integrin- $\alpha_{v}$ was increased. The qRT-PCR analysis confirms the downregulation of 6 genes associated with cell-cell contacts and cell-matrix adhesion (Figure 1B, 1C).

Another category that defines the functionality of $\mathrm{BBB}$ is the expression of transporters. We observed that TNF $\alpha$ and IFN $\gamma$ reduced the expression of 50 transporters at the mRNA level, including ABCB1 (P-glycoprotein, P-gp), ABCG2 and SLC2A1 (Glut-1) (Figure 1D, Additional file 2: Table S2). Conversely, 25 mRNA transcripts that code for transporters were increased, including the chemoresistant tranporter ABCB8 and the glucose transporter SLC2A3 (Glut-3) (Figure 1D, Additional file 2: Table S2). These results indicate that TNF $\alpha$ and IFN $\gamma$ remarkably affect the brain endothelial gene expression pattern of cell-cell contacts, cell-matrix adhesion and transport barrier systems.

\section{Discussion}

Here we showed an over-view of the cellular process altered in cytokine-activated brain endothelium using mRNA array analysis. Previous studies have shown that microvascular and macrovascular human endothelium have several differences in response to inflammatory stimulus however some similarities are also shared [12,14]. In our analysis, we observed that some of the early changes in the gene expression pattern induced by TNF $\alpha$ in HUVECs $[11,12,14]$ were also seen during long-term exposure to TNF $\alpha$ and IFN $\gamma$ in hCMEC/D3 cells. These include the positive regulation of chemokines, CAMs, apoptosis genes, complement and coagulation cascades $[11,12,14]$. Furthermore, among the CAMs upregulated by TNF $\alpha$ and IFN $\gamma$ we identified 


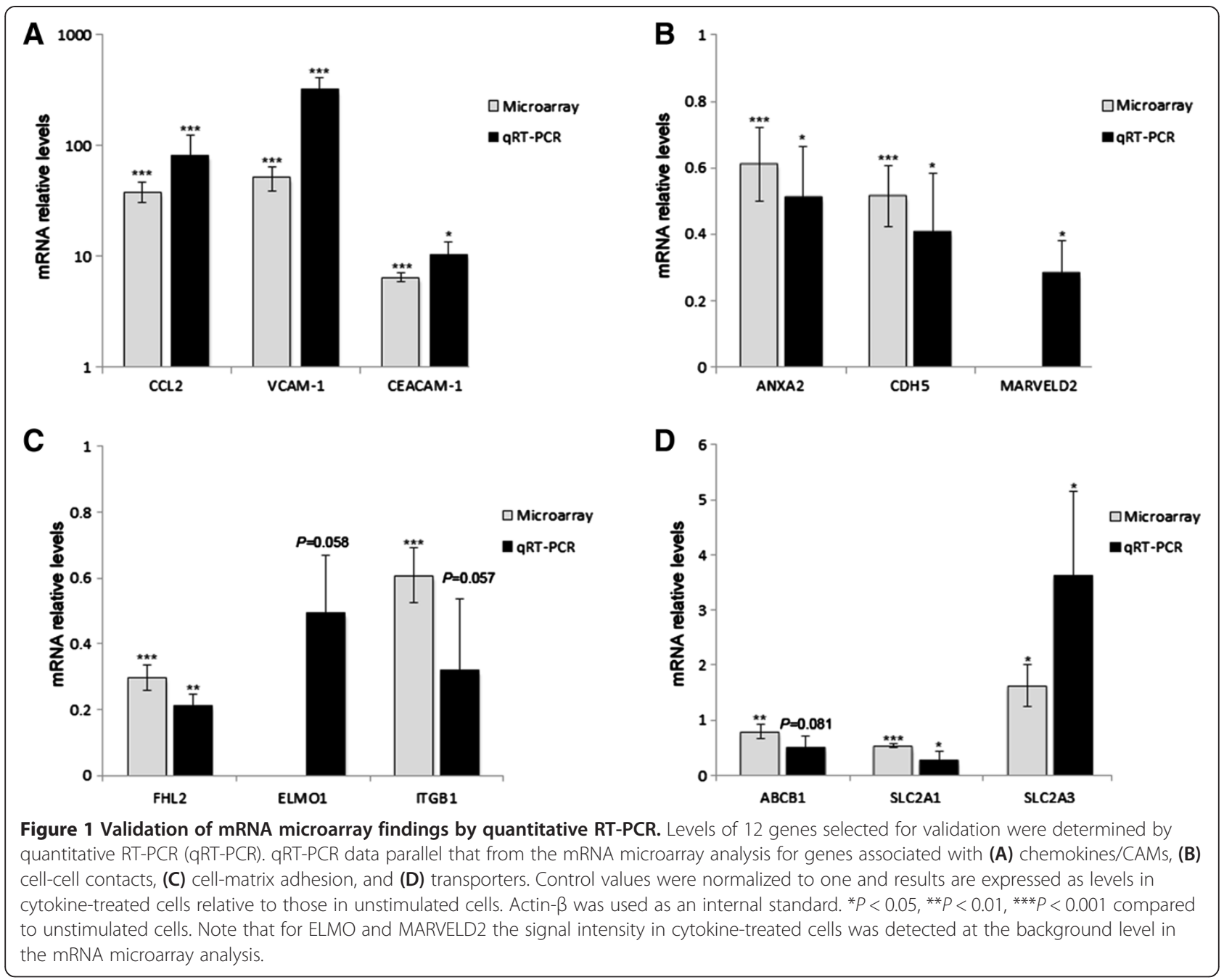

CEACAM-1, a molecule involved in angiogenesis and vascular permeability [15], although its role in brain endothelial barrier function have not been explored yet. In addition, we recently reported that the ability of CEC to respond to inflammatory stimuli by changing the pattern of gene expression is in part controlled by transcriptional activity $[8,9]$ and in part at the post-transcriptional level via small non coding RNAs termed microRNAs [16,17]. For instance, miR-155 overexpression in hCMEC/D3 cells reflects the activated state of CEC induced by TNF $\alpha$ and IFN $\gamma$, these include upregulation of genes associated with antigen presentation, CAMs, complement pathways, cytokine activity and barrier breakdown [17].

One molecular mechanism associated with cytokineinduced endothelial barrier dysfunction is reorganization of both cytoplasmic and transmembrane JCM from the cell-cell contacts $[8,18]$. Here, we observed by gene expression profiling in hCMEC/D3 cells that stimulation with TNFa and IFN $\gamma$ for $24 \mathrm{~h}$ altered mRNA levels of several JCM including claudin-5 and MARVELD-2 (also known as tricellulin), both previously reported to be enriched in CECs [19]. Indeed, we recently reported that changes in paracellular permeability and transendothelial electrical resistance correlated with changes in the expression of claudin-5 at the transcript and protein level $[8,9]$. Another molecular mechanism associated with loss of endothelial barrier integrity is rearrangement of integrinfocal adhesion complexes [20,21]. Our data supports the hypothesis that FA constitute a novel pathway that is critical for BBB maintenance [13] as many FA components were modulated by cytokines in CECs. For instance, integrin $ß 1$ serves as a platform to establish focal contacts and is downregulated by cytokines in hCMEC/D3 cells. In addition, loss of integrin $ß 1$ might also affect claudin-5 protein levels [22] and thus the brain endothelial barrier [8].

We have considered some potential criticisms of the interpretations given above. First, high concentrations of TNF $\alpha$ and IFN $\gamma$ induce an increase in CEC paracellular permeability associated with caspase-3/-7 activation and apoptotic cell death [8]. We cannot discard the possibility 
that some of the effects observed in this analysis might be secondary to a small loss of cell viability. However, our gene expression profile and the altered expression of BBBassociated genes in hCMEC/D3 cells after cytokine treatment correlate well with a recent report [23]. A second possible drawback is that most of the changes in the gene expression pattern reported here need to be further validated. However, the altered levels observed in 12 genes after cytokine-treatment within 4 functional pathways were validated by qRT-PCR. We observed that three genes analyzed, ELMO1, ITGB1 and ABCB1, were always downregulated after cytokine-treatment, but their fold changes were variable. In addition, some of the functional consequences of TNF $\alpha$ and IFN $\gamma$ on CEC have been reported. For instance, in agreement with our findings, Poller et al. [4] showed that TNF $\alpha$ reduced expression of BCRP (ABCG2) mRNA levels, protein levels and functional activity [4]. Additionally, we previously demonstrated that CCL2, CXCL10 and CCL5 protein expression is upregulated by stimulation with TNF $\alpha$ and IFN $\gamma$ in hCMEC/D3 cells [24] and that these chemokines have also been detected in MS plaques [24]. Similar to our results Pan et al. [25] reported that TNFo induced an increased in IL-15 and its receptor, IL15RA, in rat brain endothelial cells suggesting an important role of this interleukin in the brain endothelial response to cytokines [25] that is conserved between species.

In summary, pro-inflammatory cytokines might alter the highly selective barrier permeability of brain endothelial cells by establishing a new pattern of gene expression. Changes in expression of CEC genes involve biological processes associated with regulation of leukocyte infiltration, inter-brain endothelial junctions, integrin-focal adhesions and transport systems. This analysis provides insight into key molecular and cellular processes altered during neuroinflammation.

\section{Additional files}

Additional file 1: TNFa and IFN $\gamma$-induced modulation of gene expression profile of cultured human brain endothelium.

Additional file 2: TNFa and IFNp-induced modulation of transcripts related to BBB permeability.

\section{Abbreviations}

BBB: Blood-brain barrier; hCMEC/D3: The human cerebral microvascular endothelial cell line; CEC: Cerebral endothelial cells; CNS: Central nervous system; CAM: Cell adhesion molecules; HLA: Human leukocyte antigen; JCM: Junctional complex molecules; FA: Focal adhesion.

\section{Competing interests}

The authors declare that they have no competing interests.

\section{Authors' contributions}

MALR, performed research, analyzed and interpreted the data; IAR, DKM, DW, $\mathrm{BS}$, and CW, provided support with analysis of data and interpretation of results; DW and CW performed validation of array analysis; MALR, DKM, and
IAR designed the study and wrote the manuscript. All authors read and approved the final manuscript.

\section{Acknowledgments}

The authors are grateful to Julia Barkans for general laboratory infrastructure assistance and Sreekanthreddy Peddagangannagari for helpful discussions. This work was funded by the Multiple Sclerosis Society of Great Britain and Northern Ireland.

\section{Author details}

${ }^{1}$ Department of Life, Health \& Chemical Sciences, The Open University, Milton Keynes MK7 6AA, UK. ²Department of Neurology, Sheffield Teaching Hospitals NHS Trust, University of Sheffield, Sheffield, UK. ${ }^{3}$ Present address; Yale Cardiovascular Research Center, Section of Cardiovascular Medicine, Yale University, School of Medicine, New Haven, USA.

Received: 26 April 2013 Accepted: 9 September 2013 Published: 19 September 2013

\section{References}

1. Coureuil M, Mikaty G, Miller F, Lecuyer H, Bernard C, Bourdoulous S, Dumenil G, Mege RM, Weksler BB, Romero IA, Couraud PO, Nassif X: Meningococcal type IV pili recruit the polarity complex to cross the brain endothelium. Science 2009, 325:83-87.

2. Fletcher NF, Wilson GK, Murray J, Hu K, Lewis A, Reynolds GM, Stamataki Z, Meredith LW, Rowe IA, Luo G, Lopez-Ramirez MA, Baumert TF, Weksler B, Couraud PO, Kim KS, Romero IA, Jopling C, Morgello S, Balfe P, McKeating JA: Hepatitis $C$ virus infects the endothelial cells of the blood-brain barrier. Gastroenterology 2012, 142:634-643.

3. Bahbouhi B, Berthelot L, Pettre S, Michel L, Wiertlewski S, Weksler B, Romero IA, Miller F, Couraud PO, Brouard S, Laplaud DA, Soulillou JP: Peripheral blood CD4+ T lymphocytes from multiple sclerosis patients are characterized by higher PSGL-1 expression and transmigration capacity across a human blood-brain barrier-derived endothelial cell line. J Leukoc Biol 2009, 86:1049-1063.

4. Poller B, Drewe J, Krahenbuhl S, Huwyler J, Gutmann H: Regulation of BCRP (ABCG2) and P-glycoprotein (ABCB1) by cytokines in a model of the human blood-brain barrier. Cell Mol Neurobiol 2010, 30:63-70.

5. Tai LM, Reddy PS, Lopez-Ramirez MA, Davies HA, Male DK, Loughlin AJ, Romero IA: Polarized P-glycoprotein expression by the immortalised human brain endothelial cell line, hCMEC/D3, restricts apical-to-basolateral permeability to rhodamine 123. Brain Res 2009, 1292:14-24.

6. Schreibelt G, Kooij G, Reijerkerk A, van Doorn R, Gringhuis SI, van der Pol S, Weksler BB, Romero IA, Couraud PO, Piontek J, Blasig IE, Dijkstra CD, Ronken $E$, de Vries HE: Reactive oxygen species alter brain endothelial tight junction dynamics via RhoA, PI3 kinase, and PKB signaling. FASEB J 2007, 21:3666-3676

7. Afonso PV, Ozden S, Prevost MC, Schmitt C, Seilhean D, Weksler B, Couraud PO, Gessain A, Romero IA, Ceccaldi PE: Human blood-brain barrier disruption by retroviral-Infected lymphocytes: role of myosin light chain kinase in endothelial tight-junction disorganization. J Immunol 2007, 179:2576-2583.

8. Lopez-Ramirez MA, Fischer R, Torres-Badillo CC, Davies HA, Logan K, Pfizenmaier K, Male DK, Sharrack B, Romero IA: Role of caspases in cytokine-induced barrier breakdown in human brain endothelial cells. J Immunol 2012, 189:3130-3139.

9. Forster C, Burek M, Romero IA, Weksler B, Couraud PO, Drenckhahn D: Differential effects of hydrocortisone and TNF\{alpha\} on tight junction proteins in an in vitro model of the human blood-brain barrier. J Physiol 2008, 586:1937-1949.

10. Huang DW, Sherman BT, Lempicki RA: Systematic and integrative analysis of large gene lists using DAVID bioinformatics resources. Nat Protocols 2008, 4:44-57.

11. Viemann D, Goebeler M, Schmid S, Klimmek K, Sorg C, Ludwig S, Roth J: Transcriptional profiling of IKK2/NF-kappa B- and p38 MAP kinasedependent gene expression in TNF-alpha-stimulated primary human endothelial cells. Blood 2004, 103:3365-3373.

12. Franzen B, Duvefelt $K$, Jonsson $C$, Engelhardt B, Ottervald J, Wickman M, Yang Y, Schuppe-Koistinen I: Gene and protein expression profiling of human cerebral endothelial cells activated with tumor necrosis factoralpha. Brain Res Mol Brain Res 2003, 115:130-146. 
13. Kraft P, Benz PM, Austinat M, Brede ME, Schuh K, Walter U, Stoll G, Kleinschnitz C: deficiency of vasodilator-stimulated phosphoprotein (VASP) increases blood-brain-barrier damage and edema formation after ischemic stroke in mice. PloS one 2010, 5:e15106.

14. Viemann D, Goebeler M, Schmid S, Nordhues U, Klimmek K, Sorg C, Roth J: TNF induces distinct gene expression programs in microvascular and macrovascular human endothelial cells. J Leukoc Biol 2006, 80:174-185.

15. Nouvion AL, Oubaha M, Leblanc S, Davis EC, Jastrow H, Kammerer R, Breton V, Turbide C, Ergun S, Gratton JP, Beauchemin N: CEACAM1: a key regulator of vascular permeability. J Cell Sci 2010, 123:4221-4230.

16. Reijerkerk A, Lopez-Ramirez MA, van het Hof B, Joost AR, Drexhage WK, Kooij G, Joost BV, van der Pouw Kraan TCTM, Anton J, Van Z, Horrevoets AJ, Prat A, Romero IA, de Vries HE: microRNAs regulate human brain endothelial cell barrier function in inflammation: implications for multiple sclerosis. J Neurosci 2013, 16:6857-6863.

17. Lopez-Ramirez MA: Investigating the role of inflammation-modulated microRNAs and signalling pathways in blood-brain barrier dysfunction. PhD Thesis, The Open University, Department of Life, Health and Chemical Sciences. ; 2012.

18. McKenzie J, Ridley A: Roles of Rho/ROCK and MLCK in TNF-alpha-induced changes in endothelial morphology and permeability. J Cell Physiol 2007, 213:221-228.

19. Daneman R, Zhou L, Kebede AA, Barres BA: Pericytes are required for blood-brain barrier integrity during embryogenesis. Nature 2010, 468:562-566.

20. Alexander JS, Elrod JW: Extracellular matrix, junctional integrity and matrix metalloproteinase interactions in endothelial permeability regulation. J Anat 2002, 200:561-574.

21. Schlegel N, Waschke J: Impaired integrin-mediated adhesion contributes to reduced barrier properties in VASP-deficient microvascular endothelium. J Cell Physiol 2009, 220:357-366.

22. Osada T, Gu YH, Kanazawa M, Tsubota Y, Hawkins BT, Spatz M, Milner R, Del Zoppo GJ: Interendothelial claudin-5 expression depends on cerebral endothelial cell-matrix adhesion by beta(1)-integrins. J Cereb Blood Flow Metab 2001, 31:1972-1985.

23. Urich E, Lazic SE, Molnos J, Wells I, Freskgard PO: Transcriptional profiling of human brain endothelial cells reveals key properties crucial for predictive in vitro blood-brain barrier models. PloS One 2012, 7:e38149.

24. Subileau E, Rezaie P, Davies H, Colyer F, Greenwood J, Male D, Romero I: Expression of chemokines and their receptors by human brain endothelium: implications for multiple sclerosis. J Neuropathol Exp Neurol 2009, 68:227-240.

25. Pan W, Yu C, Hsuchou H, Khan RS, Kastin AJ: Cerebral microvascular IL15 is a novel mediator of TNF action. J Neurochem 2009, 111:819-827.

doi:10.1186/2045-8118-10-27

Cite this article as: Lopez-Ramirez et al: Cytokine-induced changes in the gene expression profile of a human cerebral microvascular endothelial cell-line, hCMEC/D3. Fluids and Barriers of the CNS 2013 10:27.

\section{Submit your next manuscript to BioMed Central and take full advantage of:}

- Convenient online submission

- Thorough peer review

- No space constraints or color figure charges

- Immediate publication on acceptance

- Inclusion in PubMed, CAS, Scopus and Google Scholar

- Research which is freely available for redistribution

Submit your manuscript at www.biomedcentral.com/submit
Ciomed Central 